\title{
Health Related Quality of Life in Patients with Diabetes: Psychological and Socio-Demographical Determinants
}

\author{
Sara Miftari Sadiki \\ University of Tetovo, PhD in Psychology, the Faculty of Philosophy
}

\begin{abstract}
:
Background: Diabetes mellitus disease is the universal principal cause for decreased quality of life in adulthood. This study seeks to indicate the psychological and socio-demographical determinants of the health related quality of life in patients with diabetes mellitus in Tetovo.Material and method: The research instrument used consists of socio-demographic questions and four tests: Cohen's stress measurement questionnaire, Beck's depression measurement questionnaire, Beck's anxiety measurement questionnaire and the quality of life measurement questionnaire (WHOQOL-Breef ). The sample of the study consists of $\mathrm{N}=100$, including patients with diabetes mellitus treated in Clinical Hospital in Tetovo.Results: Findings revealed that psychological variables (stress, depression and anxiety) indicates significant negative correlations with quality of life and its dimension. In terms of demographic variables, duration of disease is in significant correlation with QOL and psychological variables, type of duration is in significant correlation with QOL, age is in negative significant correlation with stress and QOL. There was no significant role at prediction of health related quality of life in terms of patient's age, gender, residence, employed, education and marital status. Conclusion: Demographic variables, such as: gender, age, employment, education and economic class are in significant relation with stress, depression, anxiety and the quality of life of patients with diabetes, while the type of disease and its duration are in that kind of relations only with the quality of life. Thus, it is important to emphasize the worth of tailored intervention for addressing these issues in therapeutic and rehabilitation agendas. Likewise, the identification and treatment of psycho-social correlates in these patients could be very important.
\end{abstract}

Keywords: diabetes mellitus, quality of life, stress, depression, anxiety

DOI: $10.7176 / \mathrm{JEP} / 10-15-13$

Publication date:May $31^{\text {st }} 2019$

\section{INTRODUCTION}

Diabetes mellitus (DM) is a disease of global public health importance associated with high morbidity and mortality (Wee, Cheung, et al, 2005; Smith, Burnet, Neil, 2003). According to International Diabetes Federation report of 2015, about 415 million people have DM globally with the figure projected to have increased to 642 million by 2040 or maybe even doubled by the year 2040 (IDF, 2015). Health-related quality of life (HRQOL) refers to the physical, psychological and social aspects of health that are influenced by person's experience on beliefs, expectations and perceptions. Understanding these domains by health care workers has an advantage in terms of incorporating chronic disease management strategies into routine care, leading to a reduction of both morbidity and mortality, including patients in developing countries (Camacho, Anderson, Bell, 2002; Da Mata, Alvares, Diniz, 2016). The psychosocial burden of living with diabetes mellitus is considerable as it affects selfcare behaviors, leading to long term poor glycemic control, increased risk of long-term complications and poor quality of life (Rubin, Peyrot, 1999; Rosenthal, Fajardo, et al, 1998). Understanding the measurements of HRQOL as well as the factors associated with poor quality of life has a benefit in terms of improving the physical and psychosocial burden associated with DM, ultimately reducing associated costs, morbidity and mortality (Rosenthal, Fajardo, et al, 1998).

Very often, adaptation to the disease is difficult to achieve. Studies show that it takes at least a year to overcome the idea and the presence of the disease, which causes changes in the emotional state and behavior of the person, indicating symptoms of anxiety, depression and influence how this person will face the disease (Morris, 2008).

Based on studies of Joki-Begi, Tadinac, Lauri Korajlija and Hromatko (2004), in which was reported stress, depression and anxiety, can be assumed that those are the factors that affect the quality of life, even though it's outlined the: purpose of the study, analysis of the relationship between stress, depression, anxiety and quality of life in patients with coronary diseases and those with diabetes; and the question of whether there are differences in the level of stress, depression, anxiety and quality of life of both groups with relevant diseases.

The aim of this study is to recognize the quality of life on patients with diabetes under the influence of stress, depression and anxiety. The logic of this study is based on the fact that during coexistence with a diabetes mellitus, patients very often psychologically can not manage the disease, and thus tend to have stress, depression and anxiety, which reduces their life quality. 


\subsection{RESEARCH METHODOLOGY}

The world literature counts a number of studies that have analyzed the psychological aspects and the quality of life on patients with chronic diseases (Dickrns, McGowen, Percival, 2006; Durmaz, Odzemir, Akyunak, 2009; Paile, Wahlbeck, Eriksson, 2007), while similar studies are not found in Tetovo area and nationwide. Due to this incentive, this study will be one of the first studies for the corresponding area.

The dependent variable in this study is the quality of life and its dimensions: physical health, mental health, social relations and the environment (Sathvik, Parthasarathi, Narahari and Gurudev, 2008 \& Zivanovic, Stojanoska, 2012).

Independent variables are divided into two categories in general demographic characteristics and psychological constructs. General demographic characteristics include the following variables: gender, age, residence, employment, education, economic status, marital status, duration of disease and the type of disease. On the other hand, psychological constructs analysis include: stress, depression and anxiety.

Inclusion and exclusion criteria

An important issue on the selection of the sample for this study was to define the diagnosis by medical specialists in the field of endocrinology.

Inclusion criteria

The participation criteria on the study, were as follows; The patient has to be from Tetovo and its area (Tetovo's villages); Have a concrete diagnosis from a medical specialist of the field; On age between 30 to 70 years; Patients which have experienced type 1 and type 2 of diabetes; Patients with disease duration up to 5 years; Patients with a single diagnosis, non comorbid diagnosis of diseases; Patients with diabetes, but without chronic complications.

Exclusion criteria

A criteria for exclusion from this study was the duration of the disease and its type. Moreover, in such cases we have changes in psychological terms of disease management. Meanwhile, the study included patients with diabetes type 1 and 2, excluding the type of diabetes that occurs in pregnant women, due to the fact that this represents a completely different category

As regards to the duration of the disease, from the research were excluded patients with disease duration more than 5 years. The duration of disease criteria, was set in conversation with medical specialists which are familiar with the course of disease and prognosis. In order to avoid chronic complications of diabetes.

Table 1. Demographic data, related to patients suffering from diabetes mellitus

\begin{tabular}{|c|c|c|c|c|}
\hline 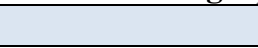 & & Frequency & Percentage & Total \\
\hline Gender & Male/Female & $50 / 50$ & $50 \% / 50 \%$ & $100 \%$ \\
\hline Age & $\begin{array}{l}30-40 / 41-50 / \\
51-60 / 61-70\end{array}$ & $\begin{array}{l}18 / 31 / \\
28 / 23 \\
\end{array}$ & $\begin{array}{l}18 \% / 31 \% / \\
28 \% / 23 \% \\
\end{array}$ & $100 \%$ \\
\hline Residency & Country/city & $33 / 67$ & $33 \% / 67 \%$ & $100 \%$ \\
\hline Civil status & $\begin{array}{l}\text { Single/married/ } \\
\text { divorced/widowed }\end{array}$ & $\begin{array}{l}8 / 90 / \\
2 / 0 \\
\end{array}$ & $\begin{array}{l}8 \% / 90 \% \\
/ 2 \% / 0 \% \\
\end{array}$ & $100 \%$ \\
\hline Education & $\begin{array}{l}\text { Non-educated/primary } \\
\text { school/secondary school/ } \\
\text { university/postgraduate }\end{array}$ & $\begin{array}{l}2 / 39 / 36 / \\
23 / 0 /\end{array}$ & $\begin{array}{l}2 \% / 39 \% / \\
36 \% / 23 \% / 0 \%\end{array}$ & $100 \%$ \\
\hline Employment & Yes/No & $51 / 49$ & $51 \% / 49 \%$ & $100 \%$ \\
\hline Economic class & Low/Middle/High & $30 / 59 / 11$ & $30 \% / 59 \% / 11 \%$ & $100 \%$ \\
\hline Disease duration & $\begin{array}{l}\text { Up to } 6 \text { months } / 6 \text { m. }-1 \mathrm{yr} \text {. } \\
/ 1 \text { yr. }-5 \mathrm{yr} \text {. }\end{array}$ & $14 / 19 / 67$ & $14 \% / 19 \% / 67 \%$ & $100 \%$ \\
\hline Disease type & Type $1 /$ Type 2 & $50 / 50$ & $50 \% / 50 \%$ & $100 \%$ \\
\hline
\end{tabular}

\subsubsection{Study procedures}

The research was conducted at Tetovo's Clinical Hospital, respectively on the relevant ambulances (units) for endocrinology diseases, within October 2014 until April 2015. Purposeful sample was selected. The entrance at the hospital, and the eased procedures to establish communication with the medical staff, were facilitated by a special permit from the director of the hospital.

Questionnaires were managed by the petitioner, and in a few cases by other interviewers (doctors or nurses) 
trained in advance by the petitioner. The researchers followed medical visits, a recent work model in hospitals of the Republic of Macedonia, which operates according to the rule "visit date", where patients at first are examined by the primary care provider (PCP) and through the electronic system are directed to a relevant medical specialist. Afterwards, the system application of Ministry of Health, messages the patients about the date and time of appointment. Thereby, we tried to choose a purposful sample. ${ }^{1}$

\subsubsection{Research tools}

Cohen's stress perception questionnary

Cohen's stress perception questionnary (PSS, Cohen, Kamarach, Mermelstein, 1983) it is one of the most popular tools for the measurement of psychological stress. It is a self reporting questionnaire, which is scheduled to measure the degree to which each individual estimates stressful situations in his life (Cohen, Janicki, 2007). PPS questionnaire assesses the degree to which the individual believes that his life was unpredictable, uncontrollable and overloaded during the last month. The questionnaire contains 10 questions in total with one answer from the alternatives offered. Questions are coded from 0 (never) to 4 (very often).

Beck's deppression assessment questionnaire (BDI)

This questionnaire was found on 1961, by Aron Beck, and finds an extensive use in the daily work with patients during clinical treatment, as well as in researches of chronic diseases (Beck, Guth, Steer and Ball, 1997 \& Steer, Cavalieri, Leonard, Beck, 1999). This questionnaire observes the mood disorders, diminished hope, the feeling of abandonment, guilt feeling, the need for punishment, self-blame, thoughts and suicidal bents, weeping, harassment, breaking relations with others, the negative picture for yourself, inability to work, sleep disruption, decreased appetite, hypochondria and decreased libido. The questionnaire contains 21 questions with four answer responding alternative, scaled from 0 to 3 .

Beck's questionnaire for the determination of anxiety (BAI). Beck questionnaire for the determination of anxiety is designed from the same materia, that Beck used to determine the depression scale. At first, the questionnaire was found to serve as a facilitator for the classification of symptoms of anxiety neurosis, but today BAI is used for tracking the changes of anxiety at any stage of the participants (Beck, 1997). It contains 21 data, which cover somatic symptoms (12 questions) and subjective evaluation of anxiety (9 questions).

Bref's questionnaire (World Health Organization Quality of Life - Bref). Bref's questionnaire is a short version of Whoqol's (0-100), a self-guide that contains 26 questions, which evaluate the quality of life in four dimensions/aspects (WHOQOL, 1998):

1.physical health (7 units);2. mental health (6 units);3. Social relations (3 units) ;4. environment (8 units).

Analysis of credibility

The credibility of a translated questionnaire can be tested by checking the internal consistency and test-retest credibility. Cronbach's alpha or coefficient of credibility, can be used to measure the internal credibility. As a rule, the Cronbach's alpha over 0.70 is considered as an acceptable credibility coefficient.

The higher is alpha or the credibility coefficient, the more reliable is the generated degree. In this study, the questionnaires showed an acceptable internal consistency, because the coefficient of Cronbach's alpha has a minimum value of .841 minimum, and a maximum value of 943 . The value of Cronbach's alpha of all questionnaires is .811 , which can be considered as relatively high.

Table 2. Analysis of credibility

\begin{tabular}{|lcc|}
\hline Questionnaire & Number of questions & Cronbach's alpha \\
\hline COHEN & 10 & .841 \\
\hline BDI & 21 & .943 \\
\hline BAI & 21 & .926 \\
\hline WHQOL & 24 & .936 \\
\hline Total analyze & 78 & .811 \\
\hline & & \\
\hline
\end{tabular}

\subsubsection{Study design}

The study was designed as quasi-experimental (almost an experiment), a method of applied research which serves to measure the impact of the independent variable on the dependent variable. The quasi experiment takes place when the researcher does not have full control of the independent variable and the control group is not equivalent to the experimental group (Goodwin, 2010). Quasi experiments are used as one of the most prevalent forms of psychology research (Campbell, 1963).

\subsection{RESULTS}

At $59 \%$ of patients with diabetes melitus were noticed high levels of stress, at $34 \%$ moderate level and only in $7 \%$

${ }^{1}$ Law on health insurance, official gazette ofRepublic of Macedonia, nr. 25/2000, 96/2000, 113/2004. 
a slight stress, Accentuated levels of depression are found at $46 \%$ of patients, while high levels are found at $35 \%$ and at $7 \%$ light level of depression, $1 \%$ of pattients werw in normal state (wihtout depression). High anxiety levels are found in $33 \%$ of patients and only $0 \%$ noticed light levels. $38 \%$ of patients with coronary disease self-reported moderated quality of life, $11 \%$ lower life quality and $40 \%$ ranked on good quality of life.

Table 3. Categories of stress, depression, anxiety and quality of life at study group

\begin{tabular}{|c|c|c|c|c|c|c|}
\hline Stress & Slight & Moderate & High & & & Total \\
\hline $\begin{array}{l}\text { Frequency } \\
\text { Percentage }\end{array}$ & $\begin{array}{l}7 \\
7 \%\end{array}$ & $\begin{array}{l}34 \\
34 \%\end{array}$ & $\begin{array}{l}59 \% \\
59 \%\end{array}$ & & & $\begin{array}{l}100 \\
100 \%\end{array}$ \\
\hline Depression & $\begin{array}{l}\text { Normal } \\
\text { state }\end{array}$ & Light & Moderate & High & Accentuated & Total \\
\hline $\begin{array}{l}\text { Frequency } \\
\text { Percentage }\end{array}$ & $\begin{array}{l}1 \\
1 \%\end{array}$ & $\begin{array}{l}7 \\
7 \%\end{array}$ & $\begin{array}{l}11 \\
11 \%\end{array}$ & $\begin{array}{l}35 \% \\
35 \%\end{array}$ & $\begin{array}{l}46 \\
46 \%\end{array}$ & $\begin{array}{l}100 \\
100 \%\end{array}$ \\
\hline Anxiety & Light & Moderate & High & & & Total \\
\hline $\begin{array}{l}\text { Frequency } \\
\text { Percentage }\end{array}$ & $\begin{array}{l}0 \\
0 \%\end{array}$ & $\begin{array}{l}67 \\
67 \%\end{array}$ & $\begin{array}{l}33 \\
33 \% \\
\end{array}$ & & & $\begin{array}{l}100 \\
100 \%\end{array}$ \\
\hline QOL & $\begin{array}{l}\text { Very } \\
\text { low }\end{array}$ & Low & Moderate & Good & $\begin{array}{l}\text { Very } \\
\text { Good }\end{array}$ & Total \\
\hline $\begin{array}{l}\text { Frequency } \\
\text { Percentage }\end{array}$ & $\begin{array}{l}0 \\
0 \%\end{array}$ & $\begin{array}{l}11 \\
11 \%\end{array}$ & $\begin{array}{l}38 \\
38 \%\end{array}$ & $\begin{array}{l}40 \\
40 \% \\
\end{array}$ & $\begin{array}{l}11 \\
11 \% \\
\end{array}$ & $\begin{array}{l}100 \\
100 \% \\
\end{array}$ \\
\hline
\end{tabular}

Stress as an independent variable at patients with diabetes indicates significant negative correlation with quality of life $(r=-596, p<001)$, with a moderated strength connection. Stress also indicates negative significant correlation with quality of life dimensions and the physical health $(\mathrm{r}=-535, \mathrm{p}<001)$ with a moderated strength connection; mental health $(r=-540, p<001)$ high connection; social relations $(r=-286, p<001)$; small connection, and the environment $(r=-562, p<001)$; the connection strength in this case is high, since a significant negative relation is noticed between stress and other variables, which means that by increasing the stress we decrease the quality of life and its dimensions, reduce the physical health, mental health, social relations and environment.

The results (Table 4) indicate that depression results in significant negative with quality of life $(\mathrm{r}=-629$, $\mathrm{p}<001)$, in this case strength connection is high, as well as its dimensions, physical health $(\mathrm{r}=-656 \mathrm{p}<001)$; mental health $(r=-607, p<001)$; social relations $(r=-409, p<001)$; and environment $(r=-405, p<001)$; strength connection between depression and dimensions of quality of life is high. The higher levels of depression decrease the quality of life levels and the dimensions levels of quality of life. The greater depression is, the lower will be quality of life.

Anxiety as an independent variable in patients with diabetes indicates significant negative correlation with quality of life $(r=-611, p<001)$, the strength connection is high. A significant negative correlation it also shown with the quality of life, its dimensions, and the physical health $(\mathrm{r}=-655 \mathrm{p}<001)$; mental health $(\mathrm{r}=-595, \mathrm{p}<001)$; social relations $(r=-411, p<001)$; and environment $(r=-419, p<001)$, the strength connection in all cases is high.

Table 4. Correlative relation of stress, depression, anxiety and quality of life at the study group

\begin{tabular}{|l|l|l|l|}
\hline & Stress & Depression & Anxiety \\
\hline Quality of life & $-.553^{*}$ & $-.624^{* *}$ & $-.611^{* *}$ \\
\hline Physical health & $-.506^{*}$ & $-.656^{* *}$ & $-.655^{* *}$ \\
\hline Mental health & $-.517^{* *}$ & $-.607^{* *}$ & $-.595^{* *}$ \\
\hline Social relations & $-.274^{*}$ & $-.409^{* *}$ & $-.411^{* *}$ \\
\hline Enviroment & $-.541^{*}$ & $-.405^{* *}$ & $-.419^{* *}$ \\
\hline
\end{tabular}

\subsubsection{Correlation relation between demographic variables and study variables at diabetes mellitus} patients

We have also analyzed the relationship between independent demographic variables (gender, age, education, residence, employment, economic status, duration of illness and type of illness) and study variables stress, depression, anxiety, quality of life and its dimension. We will interpret the statistically significant correlation founded between these two groups.

Gender shows the significant positive correlation with stress $(r=258, p<001)$, depression $(r=.644, p<001)$ and anxiety $(\mathrm{r}=486, \mathrm{p}<001)$ and negative significant correlation $(\mathrm{r}=-.426, \mathrm{p}<001)$ the power of the report was average, where it is observed the female manifests the highest degree of stress, depression and anxiety and lower quality of life.

Of all psychological variables, age is in positive significant correlation with anxiety $(\mathrm{r}=203, \mathrm{p}<005)$, and in negative significant correlation with quality of life $(\mathrm{r}=-.366)$, elders with diabetes mellitus manifested the higher level of anxiety and the lower quality of life. The same situation is also with residence, noticed that residence is in negative significant correlation with depression $(\mathrm{r}=-.235, \mathrm{p}<005)$, diabetic patients who are living in village shows the higher mean score of depression.

Patients who are not employed manifested the higher scale of depression and anxiety and the poor quality of 
life, and this results is with significant correlation, the significant values between depression and employed is $(\mathrm{r}=.307, \mathrm{p}<005)$, of anxiety $(\mathrm{r}=.199, \mathrm{p}<005)$ and the negative significant correlation between employed and quality of life $(\mathrm{r}=-.373, \mathrm{p}<001)$.

The level of education have a negative significant correlation in stress $(\mathrm{r}=-.341, \mathrm{p}<001)$, in depression $(\mathrm{r}=-.399, \mathrm{p}<001)$ and anxiety $(\mathrm{r}=-.398, \mathrm{p}<001)$, the power of the report in all cases was average, diabetic patients with higher education manifested lower scale of stress, depression and anxiety and in the same time highest level of quality of life.

From table 5 we can see the negative significant correlation between economic status and stress $(r=-507$, $\mathrm{p}<001)$, the power of the report was high; depression $(\mathrm{r}=-289, \mathrm{p}<005)$ and anxiety $(\mathrm{r}=-281, \mathrm{p}<005)$ in this two cases the power of the report was low, patients with higher economic status manifested lower scale of stress, depression and anxiety, but, the higher scale of quality of life, and, in this case status economic is in positive significant correlation with quality flife $(\mathrm{r}=.504, \mathrm{p}<001)$.

Regarding of duration of disease, there are present negative significant correlation in quality of life $(r=-.373$, $\mathrm{p}<001)$, patients living with diabetic from 1 to 5 years have a lower quality of life and in the same time a higher scale of stress with positive significant correlation $(\mathrm{r}=.255, \mathrm{p}<005)$.

The type of disease is in positive significant correlation only with quality of life ( $\mathrm{r}=.264 \mathrm{p}<001)$, and with no other variables, the same results we can also notice even at the relationship with marital status with study variables.

Table 5. Correlation relation between demographic variables and study variables at diabetes mellitus patients

\begin{tabular}{|c|l|l|l|l|}
\hline & Stress & Depression & Anxiety & QOL \\
\hline Gender & $.258^{* *}$ & $.644^{* *}$ & $.486^{* *}$ & $-.426^{* *}$ \\
\hline Age & .141 & .195 & $.203^{*}$ & $-.366^{* *}$ \\
\hline Residence & -.104 & $-.235^{*}$ & -.160 & .143 \\
\hline Marital status & .079 & -.131 & -.168 & .053 \\
\hline Employed & .185 & $.307^{* *}$ & $.199^{*}$ & $-.318^{* *}$ \\
\hline Education & $-.341^{* *}$ & $-.399^{* *}$ & $-.398^{* *}$ & $.506^{* *}$ \\
\hline Duration of disease & $.255^{*}$ & .183 & .178 & $-.373^{* *}$ \\
\hline Economic status & $-.507^{* *}$ & $-.289^{* *}$ & $-.281^{* *}$ & $.504^{* *}$ \\
\hline Type of disease & -.123 & -.152 & -.184 & $.264^{* *}$ \\
\hline
\end{tabular}

1.3.2. Hierarchical linear regression for the study group

In order to examine the influence of study variables on the quality of life in the study group, it is used the regressive hierarchical analysis, modeled in 3 steps. In table 6, at first were grouped the demographic variables (gender, age, residence, employment, marital status, economic class), the coefficient of the variance explains $40 \%$ of the general results in the quality of life, of the demographic variables of great significance is the age $((\beta=-.301, t=-.201$, $\mathrm{p}<.001)$, education $(\beta=.271 ; \mathrm{t}=4.785, \mathrm{p}<.001)$, economic class $(\beta=266 ; \mathrm{t}=5.238, \mathrm{p}<.001)$ gender $(\beta=-264, \mathrm{t}=-$ $4.212, \mathrm{p}<.001)$. At second, besides the demographic variables, in the analysis is also included the variable of disease, in this case the coefficient of the variance explains $57 \%$ of the cases, where it can be noticed the highest significance of the disease $(\beta=.430, p<.001)$, economic class $(\beta=.264 ; p<.001)$ age $(\beta=-.206 ; p<.001)$ and gender $(\beta=-198 ; p<.001)$ in the quality of life.

At third, were grouped the demographic variables, the variables of disease and was also included stress, depression and anxiety. On the model of regression, the variance explains $67 \%$ of cases, where depression has the highest significance $(\beta=-8.361 ; p<001)$, the economic class continues to remain $(\beta=4958 ; p<.001)$ age $(\beta=-$ 4.594; $\mathrm{p}<.001)$ and anxiety $(\beta=-2.413 ; \mathrm{p}<.001)$. 
Table 6. The model of regression with a dependent variable in the quality of life and independent variables at the study group

\begin{tabular}{|l|l|l|l|l|l|c|}
\hline Model & $\mathrm{B}$ & Standard error & Beta & $\mathrm{t}$ & Sig. & R/Square \\
\hline 1. (Step 1) & 80.380 & 6.889 & & 11.667 & .000 & .417 \\
\hline Gender & -6.676 & 1.532 & -.264 & -4.212 & .000 & \\
\hline Age & -4.957 & .823 & -.301 & -.201 & .000 & \\
\hline Residence & -.136 & .584 & -.083 & -1.043 & .052 & \\
\hline Marital status & 1.753 & .601 & -.111 & -1.344 & .050 & \\
\hline Employment & 1.868 & 1.745 & .056 & 1.071 & .285 & \\
\hline Education & 5.137 & 1.073 & .271 & 4.785 & .000 & \\
\hline Economic Class & 7.549 & 1.441 & .266 & 5.238 & .000 & \\
\hline 2. (Step 2) & 59.788 & 6.254 & & 9.560 & .000 & .571 \\
\hline Gender & -6.573 & 1.316 & -.198 & -4.993 & .000 & \\
\hline Age & -3.382 & .724 & -.206 & -4.672 & .000 & \\
\hline Residence & -1.115 & 1.377 & -.032 & -.810 & .419 & \\
\hline Marital status & -.242 & 1.418 & -.007 & -.171 & .864 & \\
\hline Employment & .778 & 1.503 & .023 & .517 & .605 & \\
\hline Education & 3.109 & .944 & .164 & 3.295 & .001 & \\
\hline Economic Class & 7.504 & 1.239 & .264 & 6.058 & .000 & \\
\hline Disease & 8.756 & .857 & .430 & 10.217 & .000 & \\
\hline 3. (Step 3) & 89.521 & 7.064 & & 12.674 & .000 & .669 \\
\hline Gender & -1.546 & 1.306 & -.046 & -1.183 & .238 & \\
\hline Age & -2.978 & .648 & -1.81 & -4.594 & .000 & \\
\hline Residence & -.292 & 1.227 & -.008 & -.238 & .812 & \\
\hline Marital/status & .371 & 1.256 & .030 & .521 & .603 & \\
\hline Employment & .694 & 1.333 & .021 & .521 & .603 & \\
\hline Education & 1.562 & .862 & .082 & 1.813 & .071 & \\
\hline Economic Class & 6.566 & 1.123 & .196 & 4.958 & .000 & \\
\hline Disease & 2.270 & 1.230 & .111 & 1.846 & .066 & \\
\hline Stress & -.103 & .115 & -.043 & -.898 & .370 & \\
\hline Depression & -.525 & .063 & -.418 & -8.361 & .000 & \\
\hline Anxiety & -.173 & .071 & -.130 & -2.413 & .016 & \\
\hline & & & & & & \\
\hline & & & & & & \\
\hline
\end{tabular}

\subsection{Discussion}

The main purpose of this research was to ascertain whether stress, depression, anxiety in the quality of life of coronary disease patients, and we also wanted to see changes in the presence of stress, depression, anxiety, and quality of life in comparison with gender, age, residence, civil status, degree of education, employment and socioeconomic status.

In the research population we found statistically significant positive differences compared to stress levels, anxiety, depression and quality of life among the male and female sample of diabetes mellitus. Thus, it has been proven that women are more anxious and depressed, and react more with fury to stressful events than men. Similar results have also been gathered by other researchers (Ali, Stone and Peters, 2006; Maryam and Bakthiri, 2013). Also, respondents experience their illness as a powerful traumatic event (Anderson, Freeland and Clouse, 2001). Males have had higher results in all spheres of quality of life than women. These results are in line with our expectations, which coincides with other studies, where the same results are present (Jonsson, Nystrom, Sterky and Wall, 2005). However, some authors say men are the same as they are concerned with anxiety and depression, but women are more willing to seek help when they are in a situation that they do not feel good about (Gregory, 2006).

Patients with diabetes aged 51-60 have resulted in higher levels of depression, anxiety and stress as well as lower lifestyle compared to other ages. This is the stage of middle-aged crises. Under the panic that they are aging and have not experienced or fulfilled what they imagined when they were young, they try to meet their unrealized needs on the one hand and, on the other hand, efforts to cope with all its vicissitudes. By comparing age, we gained a positive correlation between the rate of anxiety and quality of life, but we do not have a correlation between stress and depression. Our prediction was fully verified: younger ones are better at expressing emotions and anticipating them, while the elderly are more sensitive and prone to the development of depression and guilt. It is characteristic that, with the progress of the illness, the person is able to live in harmony with his remaining physical abilities, and thus their somatic and psychic health is weakened, and thus the quality of life (Perveen, Otho, Siddiqi, 
Hatcher and Rafique, 2010).

Patients from rural areas are at a higher degree of depression than those in urban areas. This may be because these patients are more in need of healthy eating, for dietary and medicines, things that are easier to obtain in urban areas than in rural areas. A higher level of depression may possibly have a lower lifestyle quality. This finding complies with the studies of Kuruburan-it, Pukunan-it and Rizal-it (2015).

The level of education, as seen from the results we have achieved, seems to be another protective factor against psychological concerns in our diabetic patients.

The relationship between economic status and diabetes has been analyzed in many studies, due to the fact that even a low economic status may be the cause of the disease. (Krantz and McCeney, 2002). Low economic status is often associated with factors such as inadequate safety, poor preventive care, poor diet, and minimal care, those can cause high stress and increase the likelihood of developing depression and anxiety (Heslop, Smith, Caroll and Macleod, 2001). In our study it is noticed that a major barrier to poor economic conditions is an unmanageable problem in diabetic patients because they appear to have high levels of psychological worries and a significantly lower life expectancy than high status diabetic patients economic. This may be because patients with high economic status have better treatment options. (Sims, Roux, Boykin and Sarpong, 2011; Le, Jun, Zhankun and Yichun, 2011), a better glucose level and cholesterol in the blood (Brown, Gregg and Stevens, 2005) and a lower probability for secondary complications from diabetes (Secrest, Costacou and Gutelius, 2011).

Poor psycho-social factors, low levels of education, unemployment, stress and social marginalization are predictors of anxiety and depression, affecting the quality of life of people with diabetes. Depression in patients with diabetes mellitus increases the risk of complications, reduces the quality of life, the ability to enjoy life, the normal professional and social functioning (Anderson, Freeland, Clouse and Lust Man, 2001; Paile-Hyvarinen, Wahlbec and Eriksson 2007; Skodova, Nagyova, Rosenberger and Vargova, 2008). Also, research results show that subclinical symptoms in patients cause drowsiness, and therefore people with diabetes do not adhere to selfcontrol and self-control measures (Jiang dhe Krishnan, 2002). There is no significant statistical difference between social status and psychological variables in patients suffering from diabetes mellitus, Maryam and Bakthiri (2013) have found that anxiety, depression and quality of life are not related to social status.

Most frequent medical visits occur in patients living with diabetes for 1 to 5 years: $67 \%$ of them have a higher depression level and lower life expectancy than the other two groups with longer duration of illness than 1 year. This result may be attributed to the inability of patients to treat the disease and its relatively long time. This result also supports foreign studies (Nichols and Brown, 2003; Almawi, Tamin and Baqer, 2008). Regarding the duration of the disease, adult stress is an important factor, which has a negative effect on lifestyle quality and control of blood glucose). Wisit-i, Natchapon-i, Frank-u (2008), Rohin-i, Trupti and Samir-i (2001) have achieved similar results in their studies regarding the duration of diabetes mellitus and quality of life. Insulin-dependent diabetes has a positive correlation in all spheres of quality of life, compared to insulin-free diabetes.

However, this has to do with the use of insulin, but also with the fear that after a period of time the disease may get out of control and the blood glucose level will rise again.

Stress and anxiety do not correlate with the type of illness, and therefore we rely on our studies Kawachi-t, Coldit-it, Ascherio-s and Rimm-it (1994). Patients with type 1 diabetes and patients with myocardial infarction are the group most suffering from depression and low quality of life. A similar result is also found in the studies Greenit, Arbor-it, Dickinson-it (2009), Speight-it, Browne-it, Holmes-it and Pouwer-it, (2011) This certainly affects the overall assessment of living, which includes all relevant criteria that are relevant to the individual (O'Donoghue, Boden and Braunwald, 2008).

\subsection{Recommendations}

This study proves that patients with diabetes simultaneously suffer from anxiety, depression and the average quality of life; that is way these results can be orientated to help in the psychological aspect, in psycho-therapeutic advice and functions, so that the disease can be accepted and overcome easier (Lane, Chong, 2005). Hence, this study leaves space for a longitudinal study, with the aim to analyze the patients with chronic disease before and after the role of the psychologist/psychiatrist, by psycho therapies and advices, in order to see if there are improvements in the quality of life

\section{References:}

1. Ali, S., Stone, M.A., Peters, J.L., Davies, M.J., Khunti, K. (2006). The prevalence of co-morbid depression in adults with Type 2 diabetes: a systematic review and meta-analysis. Diabetic Medicine, 23(11), 1165-1173

2. Almawi, W., Tamim, H., Al-Sayed, N., Arekat, MR., Al-Khateeb, GM., Baqer, A., Tutanji, H.K., (2008). Association of comorbid depression, anxiety and stress disorders with type 2 diabetes in Bahrain, a country with a very high prevalence of type 2 diabetes. $J$ Endocrinol Invest 31:1020-1024

3. Anderson, R.J., Freeland, K.E., Clouse, R.E., Lust, Man, P.J., (2001). The prevalence of comorbid depression in adults with diabetes: a meta-analysis. Diabetes Care, 24:1069-1078. 
4. Beck, A.T., Guth, D., Steer, R.A.,Ball, R., (1997). Screening for major depression disorders in medical inpatients with the BDI for primary care, Behaviour Research Therapy,35:785-91

5. Brown, A.F, Gregg, E.W., Stevens, M.R., Karter, A.J., Weinberger, M., Safford, M.M., et al. (2005). Race, ethnicity, socioeconomic position, and quality of care for adults with diabetes enrolled in managed care: the Translating Research Into Action for Diabetes (TRIAD) study. Diabetes Care.;28:2864-70.

6. Camacho F, Anderson RT, Bell RA, et al. (2002) Investigating correlates of health related quality of life in low-income sample of patients with diabetes. Qual Life Res; 11:783-796.

7. Cohen., S., Kamarach, T., Mermelstein, R.,(1983). A global measure of perceived stress. Journal of Health and Social behavior, 24,385-396.

8. Cohen, S., Janicki-Deverts, D., (2007). Miller, G.E. Psychological stress and disease. Journal of theAmerican medical Association, 298, 1684-1681

9. Da Mata AR, Alvares J, Diniz LM, et al. (2016) Quality of life of patients with diabetes mellitus types 1 and 2 from a referal health centre in Minas Gerais, Brazil. Expert Rev Clin Pharmacol.;9 (5):739-746

10. Dickrns, M.C., McGowen, L., Percival, C., (2006). Contribution of depression and anxiety to impared healthrelated quality of life following first myocardial infarction. Br J Psychiatry, 189:367-372.

11. Durmaz, T., Ozdemir, O., Ozdemir, A.B., Keles, T., Bayram, A.N., Bozkurt, E., (2009). Factor affecting quality of life in patients with coronary heart disease. Turk J Med Sci, 39(3):343-51.

12. Green, A.L., Arbor A., Dickinson, P.W., Nease, E.D., Schellhase G.K., Campos-Outcalt D., et al. (2009). Guideline for detection and management of post-myocardial infarction depression. Ann Fam Med;7:71-9.

13. Gregory, R., (2006). Suradnja i konsultativna psihologija. Zagreb: Skolska knjiga.

14. Heslop, P., Smith, G.D., Carroll, D., Macleod, J., Hyland, F. \& Hart, C. (2001). Perceived stress and coronary heart disease risk factors: The contribution of socio-economic position, British Journal of Health Psychology,6(2),167-178.

15. IDF. IDF diabetes atlas: global estimates of the prevalence of diabetes for 2015 and 2040. Available at URL:

16. Jiang W, Krishnan RR. (2002). Depression and healt disease of a link and its therapeutic implications. CNSDrugs, 16:111-27.

17. Jonsson, P.M., Nystrom, L., Sterky, G., Wall, S., (2005). Sociodemographic predictors of self rated health in patients with diabetes of short duration. Scand J Public Health, 29:263-270.

18. Joki-Begi, N., Tadinac, M., Lauri Korajlija, A. i Hromatko, I., (2004). Anxiety as a Predictor of the Subjective Quality of Life. STAR, Konferencija, Amsterdam.

19. Kawachi, I., Colditz, G.A., Ascherio, A., Rimm, E.B., Giovannucci, E., Stampfer, M.J., Willett, W.C., (1994). Prospective study of phobic anxiety and risk of coronary heart disease in men Circulation; 89:1992-1997.

20. Krantz, D.S., Kop, W.J., Santiago, H.T., Gottdiener, J.S., (1996). Mental stress as a trigger of myocardial ischemia and infarction. Cardiology Clinics, 14:271-287.

21. Kuruburan, G., Pukunan, R.,Rizal, A., (2015), Factors associated with anxiety and depression among type 2 diabetes outpatients in Malaysia: a descriptive cross sectional single enter study, BMJ Open 2014;4:004794.

22. Lane DA, Chong AY, Lip GYH. (2005), Psychological interventions for depression in heart failure. Cochrane Database Syst Rev ; (1): CD003329

23. Maryam, P., Maryam, Bakthiri., (2013). Association of depression and anxiety with diabetes mellitus type 2 concerning some socioligical Factors, Iranian Red Crescent Medical Jorunal, Agust 15 (8):644-8

24. Morris, Ch.G., Maisto, A.A., (2008).Psikologjia ,shkenca e proceseve mendore dhe e sjelljes njerëzore. Qendra për Arsim Demokratik, Tiranë, , fq 399)

25. Nichols, G.A., Brown, J.B., (2003). Unadjusted and adjusted prevalence of diagnoseddepression in type 2 diabetes. Diabetes Care 26(3):744-749

26. O’Donoghue, M., Boden, WE, Braunwald E, Cannon CP, Clayton TC, deWinter RJ, et al.( 2008). Early invasive vs conservative treatment strategies in women and men with unstable angina and non-ST-segment elevation myocardial infarction: a meta-analysis. JAMA;300(1):71-80.

27. Paile-Hyvarinen, M., Wahlbeck, K., Eriksson, J.G., (2007). Quality of life and metabolitic status in mildly depressed patients with type 2 diabetes treated with paroxetine: a double-blind randomized controlled 6month trial. BMC Fam Pract, 15:8-34.

28. Rohin, R., Trupti, N., Samir,D.B, (2001). Social class differentiation and its impact on quality of life among diabtic patients, National Journal of Community Medicine Vol 2 Numer 3 Oct-Dec fq. 362.

29. Rosenthal MJ, Fajardo M, Gilmore S, Morley JE, Nabiloff BD. Hospitalization and mortality of diabetes in older adults: a three-year prospective study. Diabetes Care. 1998; 21:231-235.

30. Rubin RR, Peyrot M. (1999) Quality of life and diabetes. Diabetes/Metabolism Res Rev.;15(2):205-218.

31. Sathvik, Parthasarathi, Narahari , Gurudev, (2008). An assesment of the quality of life in hemodialysis patients using the WHOQOL-BREF qustionere. Indian journal of Nephrology, vol 18/issue 4, fq 140-149.

32. Secrest, A.M., Costacou, T., Gutelius, B., Miller, R.G., Songer, T.J., Orchard, T.J.,(2011). Association of socioeconomic status with mortality in type 1 diabetes: the Pittsburgh epidemiology of diabetes complications 
study. Ann Epidemiol.21:367-73

33. Sims, M., Diez, Roux, A.V., Boykin, S., Sarpong, D., Gebreab, S.Y., Wyatt, S.B., et al. (2011). The socioeconomic gradient of diabetes prevalence, awareness, treatment, and control among African Americans in the Jackson Heart Study. Ann Epidemiol.21:892-8.

34. Skodova, Z., Nagyova, I., Rosenberger, J., Vargova, H., (2008). Vital exhaustion in coronary heart disease: The impact of socioeconomic status. European Journal of Cardiovascular Prevention and rehabilitation, 15(5):572-576.

35. Smith LL, Burnet SP, McNeil JD. (2003)Musculoskeletal manifestations of diabetes mellitus. Br J Sports Med.;37(1):30-35 International Diabetes Federation on Botswana. . Accessed on 26th February 2017; 2015.

36. Speight, J., Browne, J.L., Holmes-Truscott, E., Hendrieckx, C., Pouwer, F. (2011). On behalf of the Diabetes MILES - Australia reference group. Diabetes MILES - Australia Survey Report. Melbourne: Diabetes Australia.

37. Zivanovic D, Stojanoska M, (2012), Quality of life in patient with diabetes mellitus type, Vojnosanit Pregl; 69 (10): 8585-863.

38. Wee H-L, Cheung Y-B, Li S-C, Fong K-Y, (2005) Thumboo J. The impact of diabetes mellitus and other chronic medical conditions on health-related quality of life: is the whole greater than the sum of its parts? Health Qual Life Outcomes.;3:2.

39. Wisit, C., Natchapon, P.,Frank,.P.S., (2008). Quality of life and complince among type 2 diabtic patients, Southeast Asian J Trop Med Public Health, Vol 39, nr 2.

40. WHOQOL, Measuring Quality of Life. (1997). Division of mental health and prevention of substance abuse, World health organization. 